(caloric restriction), rather than metabolism of macronutrients, are associated with the maintenance of weight loss.

Although intensive-support programs may be more costly than nurse-supported programs, the true cost and, more importantly, the cost-effectiveness of these programs are unknown. The feasibility of implementing nurse-coordinated programs within different settings is unclear. Challenges in Canada include a paucity of nurses, who are already faced with heavy workloads. The nurse in the study by Dale and colleagues had little training in nutrition and exercise but was supportive and enthusiastic. Thus, the content, approach and frequency of care provided in support programs may be more important than who provides it. The findings of Dale and colleagues support the inclusion of exercise specialists and dieticians in the care of overweight and obese adults, because these health professionals have the relevant training, are no more expensive than nurses, and would be enthusiastic supporters of their nursing colleagues. Dale and colleagues deserve much credit for showing that clinically meaningful weight loss can be maintained for an extended period in a pragmatic manner. Although the challenges inherent to the treatment of obesity are real, so too are the opportunities.

\section{REFERENCES}

1. Lau DC, Douketis JD, Morrison KM, et al.; for the Obesity Canada Clinical Practice Guidelines Expert Panel. 2006 Canadian clinical practice guidelines on the management and prevention of obesity in adults and children [executive summary]. CMAJ 2007; 176:S1-13.

2. Weiss EC, Galuska DA, Kettel Khan L, et al. Weight regain in U.S. adults who experienced substantial weight loss, 1992-2002. Am J Prev Med 2007;33:34-40.

3. Dale KS, McAuley KA, Taylor RW, et al. Determining optimal approaches for weight maintenance: a randomized controlled trial. CMAJ 2009;180:1015-20.

4. Svetkey LP, Stevens VJ, Brantly PJ, et al.; Weight Loss Maintenance Collaborative Research Group. Comparison of strategies for sustaining weight loss: the weight loss maintenance randomized controlled trial. JAMA 2008;299:1139-48.

5. Wing RR, Tate DF, Gorin AA, et al. A self-regulation program for maintenance of weight loss. $N$ Engl J Med 2006;335:1563-71.

6. Wing RR, Papandonatos G, Fava JL, et al. Maintaining large weight losses: the role of behavioral and psychological factors. J Consult Clin Psychol 2008;76: 1015-21.

7. Ross R, Janiszewski PM. Is weight loss the optimal target for obesity-related cardiovascular disease risk reduction? Can J Cardiol 2008;24 Suppl D:25D-31D.

8. Lawton BA, Rose SB, Raina Elley C, et al. Exercise on prescription for women aged 40-74 recruited through primary care: two year randomised controlled trial. Br J Sports Med 2009;43:120-3.

9. Sacks FM, Bray GA, Carey VJ, et al. Comparison of weight-loss diets with different compositions of fat, protein, and carbohydrates. N Engl J Med 2009;360:859-73.

Correspondence to: Dr. Robert Ross, School of Kinesiology and Health Studies, Medicine, Division of Endocrinology and Metabolism, Queen's University, 69 Union St., Kingston ON

K7L 3N6; rossr@post.queensu.ca

\title{
What kind of randomized trials do we need?
}

\section{Merrick Zwarenstein MD MSc, Shaun Treweek BSc PhD}

Published at www.cmaj.ca on Apr. 16, 2009. This article was published simultaneously in the May 2009 issue of the Journal of Clinical Epidemiology (www.jclinepi.com).

$\infty$ See related article by Thorpe and colleagues, page E47, and commentary by Maclure and colleagues, page 1001

I n 1967, Daniel Schwartz and Joseph Lellouch, 2 French statisticians, and their British colleague and translator Michael Healy wrote "[M]ost therapeutic trials are inadequately formulated, and this from the earliest stages of their conception."

The seminal paper ${ }^{1}$ from which this dramatic assertion is drawn is reprinted in the May 2009 issue of the Journal of Clinical Epidemiology as part of a joint focus with CMAJ on making randomized controlled trials (RCTs) more useful.

Schwartz and Lellouch argued that there are 2 kinds of randomized trials embodying radically different attitudes to evaluation of treatment, which they named "pragmatic" and "explanatory." They go on to say that these 2 attitudes require different approaches to the design of a randomized trial. The pragmatic attitude seeks to directly inform realworld decisions among alternative treatments. Schwartz and Lellouch show that this purpose is satisfied in trials that se- lect typical participants, settings and comparator care to widen real-world applicability. In contrast, the explanatory attitude seeks to understand a biological process by testing the hypothesis that the specified biological response is explained by exposure to a particular treatment. Tight restrictions on participants, treatment, control and setting maximize the contrast with the control group and increase the ability to test this kind of hypothesis.

Their assertion of inadequate formulation relates to the mismatch between the use we make of most trials (which is to inform decisions on therapy) and the design of these trials (which generally takes the opposite form, best suited to test-

Merrick Zwarenstein is with the Centre for Health Services Sciences, Sunnybrook Research Institute, Toronto, Ont. Shaun Treweek is with the Division of Clinical and Population Science and Education, University of Dundee, Dundee, UK. 
ing causal hypotheses). This mismatch between the clinical context in which clinicians must make decisions and the clinical context of the randomized trials that they must use for evidence means that health professionals (and, writ large, health care funders) are left without direct evidence upon which to base most of the patient care decisions (and funding decisions) that each must make. Since information from an explanatory trial is unlikely to inform a pragmatic question, nor vice versa, Schwartz and Lellouch proposed that investigators should explicitly specify the purpose of their trial and design it to match that purpose.

There are few trials whose purpose and design choices match. The only review of this subject ${ }^{2}$ identified fewer than 100 pragmatic designed randomized trials, of the quarter million or so RCTs listed by the US National Library of Medicine, which suggests that existing RCTs are mostly explanatory in design and thus not directly applicable to choosing between treatment options. This is ironic since the very first published randomized trial was pragmatic in purpose and in many of its design choices. It showed clear benefits for patients receiving streptomycin and usual care (bed rest) over the control group receiving only usual care. ${ }^{3}$ The decline of tuberculosis in high-income countries is thus due in part to the pragmatic trial.

Why so few pragmatic trials? Because of the size of the market, US pharmaceutical licensing regulations are the principal stimulus for the conduct of RCTs of treatments and the main influence on their design. The requirement that pharmaceutical manufacturers demonstrate efficacy of their products was first legislated in the 1962 Kefauver-Harris amendments to the US Federal Food, Drug, and Cosmetic Act, passed in the wake of the thalidomide tragedy, from which the United States had been largely spared by caution on the part of the US Food and Drug Administration (FDA). ${ }^{4}$ Perhaps because of their focus on safety, these licensing regulations ${ }^{5}$ devote most of their attention to preparatory studies in animals, safety issues in humans and documentation. The little guid- ance there is argues against trials with a pragmatic attitude: "One problem [with active-control trials] is that there are numerous ways of conducting a study that can obscure differences between treatments, such as poor diagnostic criteria, poor methods of measurement, poor compliance, medication errors, or poor training of observers. As a general statement, carelessness of all kinds will tend to obscure differences between treatments. Where the objective of a study is to show a difference, investigators have powerful stimuli toward assuring study excellence." ${ }^{\prime \prime}$ Much of what the FDA labels "careless" or "poor" is typical in usual care. The FDA thus equates pragmatic design choices aimed at increasing applicability with carelessness and poor study design, which results in trials that lack the attributes needed to directly support decisions about the real-world usefulness of a treatment.

FDA regulations and guidance are influential, but 2 other factors cannot be ignored: after spending many millions of dollars on development of a therapeutic drug or device, no corporation wants to give such an investment less than an ideal setting for displaying its benefits, hence the emphasis on starkly contrasting placebo control groups - often placebo controlled, enhanced adherence and highly selected patient centres and clinicians. The shared desire of the FDA and industry for conducting trials under ideal conditions with strong contrasts is reinforced by the strong preference of the US National Institutes of Health for trials that elucidate clear physiologic hypotheses. This triangle of actors contributes to the flood of stringently conducted and internally valid randomized trials, of doubtful applicability to most patients, most settings and most clinicians.

There is disquiet about the remoteness from real-world decision-making of regulatory randomized trials ${ }^{7}$ among thirdparty funders such as Medicare in the United States, who are concerned that the potentially lower real-world benefits of a treatment might be outweighed by potentially higher risks, which would leave decisions on use and funding unclear. As a consequence, there is a rising interest in the design of trials that would avoid these misleading design attributes and pro-

Table 1: Key differences between trials with explanatory and pragmatic attitudes*

\begin{tabular}{|c|c|c|}
\hline Feature & Explanatory attitude & Pragmatic attitude \\
\hline Participants & $\begin{array}{l}\text { Highly selected; poorly adherent participants and } \\
\text { those with conditions that might dilute the effect are } \\
\text { often excluded }\end{array}$ & $\begin{array}{l}\text { Little or no selection beyond the clinical indication of } \\
\text { interest }\end{array}$ \\
\hline Comparator & Strictly enforced; adherence is monitored closely & $\begin{array}{l}\text { Often usual care, with usual variation; applied flexibly } \\
\text { as it would be in normal practice }\end{array}$ \\
\hline Outcomes & Often short-term surrogates or process measures & $\begin{array}{l}\text { Directly relevant to participants, funders, communities } \\
\text { and health care practitioners }\end{array}$ \\
\hline $\begin{array}{l}\text { Relevance } \\
\text { to practice }\end{array}$ & $\begin{array}{l}\text { Indirect: little effort is made to match the design of the } \\
\text { trial to the decision-making needs of those in the usual } \\
\text { setting in which the intervention will be implemented }\end{array}$ & $\begin{array}{l}\text { Direct: the trial is designed to meet the needs of those } \\
\text { making decisions about treatment options in the } \\
\text { setting in which the intervention will be implemented }\end{array}$ \\
\hline
\end{tabular}

*Adapted, with permission, from Zwarenstein M, Treweek S, Gagnier J, et al.; CONSORT and Pragmatic Trials in Healthcare (Practihc) groups. Improving the reporting of pragmatic trials: an extension of the CONSORT statement. BMJ 2008;337:a2390. The table in BMJ was adapted from a table presented by Marion Campbell, University of Aberdeen, at the 2008 Society for Clinical Trials meeting. 
vide, as Schwartz and Lellouch long ago suggested, direct decision-making information to those who must choose whether or not to prescribe, use, pay for or promote particular treatments.

Several papers take up this critically important theme. All appear in the May 2009 issue of the Journal of Clinical Epidemiology. The article by Thorpe and colleagues, ${ }^{8}$ which also appears in this issue of CMAJ (page E47), offers us a first draft of a means for classifying design choices as to their degree of pragmatism, important because this is not an all-ornone phenomenon. Karanicolas and colleagues ${ }^{9,10}$ argue that a trial has a fundamental "point of view" that changes the relationship between the decision-making purpose of a trial and its design. Oxman and colleagues ${ }^{11,12}$ argue the contrary, namely that patients and clinicians benefit most from having more pragmatic evidence on which to base their decisions. Finally, Maclure ${ }^{13}$ whose article also appears in this issue of CMAJ (page 1001), points to the close match between decision-makers' preferences for directly applicable evidence and the pragmatic attitude favoured by Schwartz and Lellouch. Some of these authors have also recently published an extension to the CONSORT (Consolidated Standards of Reporting Trials) statement for pragmatic trials (Table 1$),{ }^{14}$ with recommendations on reporting of trials whose aim is to inform decisions. This CONSORT extension encourages authors to include in their trial publications information to help readers judge the applicability of the results to their own settings, the better to decide whether or not to implement the tested intervention (Table 1$).{ }^{14}$

The expansion of interest in the design of pragmatic randomized trials to support decision-making is surely now much needed. In Canada, for example, the regulatory authority (Health Canada) is currently considering a progressive licensing model for therapeutic agents. ${ }^{15}$ Foremost in its consideration is speeding the process of licensing while maintaining high standards for the evaluation of safety and efficacy. Health Canada might consider revisiting its regulations and encouraging the use of pragmatic designs to support its decision-making. It might be argued that this would lengthen an already prolonged licensing process, reducing the ability of inventors to profit from their discoveries. There is a counter argument: if the initial randomized trial of a treatment were pragmatic in purpose and design, funders of the treatment could immediately use that information to make decisions on usefulness in their setting and patient group, eliminating what are today entirely separate and sequential processes for regulatory approval and formulary inclusion. Combining the trials that collect information for regulatory and for formulary inclusion processes could simplify both and make more transparent the reasons for decisions on reimbursement. And since large public funders demanding information for decisionmaking are the world's most important markets for new phar- maceuticals, this could lengthen the period of profitable patent protection, rather than shorten it.

Schwartz and Lellouch ended their paper with a devastating conclusion: "Most trials done hitherto have adopted the explanatory approach without question; the pragmatic approach would often have been more justifiable." Forty years and hundreds of thousands of randomized trials later, this remains true. It is time to shift our design choices so that they match our usual purpose in conducting a trial, most often to directly inform the decisions of real-world patients, clinicians and third-party funders.

\section{Competing interests: None declared.}

Contributors: Both of the authors were involved in the preparation of the manuscript and approved the final version submitted for publication.

\section{REFERENCES}

1. Schwartz D, Lellouch J. Explanatory and pragmatic attitudes in therapeutical trials. J Chronic Dis 1967;20:637-48. [Reprinted in J Clin Epidemiol 2009;62:499-505.]

2. Vallvé C. A critical review of the pragmatic clinical trial [Spanish]. Med Clin (Barc) 2003;27:384-8.

3. Fox W, Hill A. Streptomycin treatment of pulmonary tuberculosis. BMJ 1948;2: 769-82.

4. A brief history of the Center for Drug Evaluation and Research. Rockville (MD): Center for Drug Evaluation and Research, US Food and Drug Administration; 1997. p. 32. Available: www.fda.gov/cder/about/history/Page32.htm (accessed 2009 Feb. 12)

5. Investigational new drug application. Code of federal regulations. Title $21, \mathrm{Pt} 312$ (revised 2008 Apr. 1). Available: www.accessdata.fda.gov/scripts/cdrh/cfdocs /cfcfr/CFRsearch.cfm?CFRPart=312 (accessed 2009 Feb. 12).

6. Drug study designs. In: Drugs and biologics. Guidance for institutional review boards and clinical investigators: 1998 update [information sheet]. Rockville (MD): US Food and Drug Administration; 1998. Available: www.fda.gov/oc/ohrt /irbs/drugsbiologics.html\#study (accessed 2009 Feb. 12)

7. Tunis SR, Stryer DB, Clancy CM. Practical clinical trials: increasing the value of clinical research for decision making in clinical and health policy. JAMA 2003; 290:1624-32.

8. Thorpe KE, Zwarenstein M, Oxman AD, et al. A pragmatic-explanatory continuum indicator summary (PRECIS): a tool to help trial designers. J Clin Epidemiol 2009; 62:464-75. [Also in CMAJ 2009;180:E47-E57.]

9. Karanicolas PJ, Montori VM, Deveraux PJ, et al. A new "Mechanistic-Practical" framework for designing and interpreting randomized trials. J Clin Epidemiol 2009; 62:479-84.

10. Karanicolas PJ, Montori VM, Devereaux PJ, et al. The practicalists' response. J Clin Epidemiol 2009;62:489-94.

11. Oxman AD, Lombard C, Treweek S, et al. Why we will remain pragmatists: four problems with the impractical mechanistic framework and a better solution. J Clin Epidemiol 2009;62:485-8.

12. Oxman AD, Lombard C, Treweek S, et al. A pragmatic resolution. J Clin Epidemiol 2009;62:495-8.

13. Maclure M. Explaining pragmatic trials to pragmatic policymakers. J Clin Epidemiol 2009;62:476-8. [Also in CMAJ 2009;180:1001-3.]

14. Zwarenstein M, Treweek S, Gagnier J, et al.; CONSORT and Pragmatic Trials in Healthcare (Practihc) groups. Improving the reporting of pragmatic trials: an extension of the CONSORT statement. BMJ 2008;337:a2390.

15. Progressive licensing model. Ottawa (ON): Health Canada; 2007. Available: www.hc-sc.gc.ca/dhp-mps/homologation-licensing/model/index-eng.php (accessed 2009 Feb. 12).

Correspondence to: Dr. Merrick Zwarenstein, Centre for Health Services Sciences, Sunnybrook Research Institute, Sunnybrook Health Sciences Centre, Rm. G1-06, 2075 Bayview Ave., Toronto ON M4N 3M5; merrick.zwarenstein@ices.on.ca 